\title{
Oxidation and Protection of Fiberglass-Epoxy Composite Masts for Photovoltaic Arrays in the Low Earth Orbital Environment
}

\author{
(BASA-TE-100839) OXICATICA AXI EFOTECTIOH \\ CE PIBERGIASS-BEOIY CCEROSITE UASTS POA \\ PBCTOTCLTAIC LEEATS IN TBE LCH EARTH OABITAL \\ EEVIRONGETT (MASA) 12 P \\ CSCL 11B \\ \$88- 18734 \\ $\begin{array}{ll}\text { Gnclas } \\ \text { G } 3 / 27 & 0129540\end{array}$
}

Sharon K. Rutledge

Lewis Research Center

Cleveland, Ohio

Phillip E. Paulsen and Joyce A. Brady

Cleveland State University

Cleveland, Ohio

and

Michael L. Ciancone

Lewis Research Center

Cleveland, Ohio

Prepared for the

Spring Meeting of The Materials Research Society

Reno, Nevada, April 5-9, 1988 
OXIDATION AND PROTECTION OF FIBERGLASS-EPOXY COMPOSITE MASTS FOR PHOTOVOLTAIC ARRAYS IN THE LOW EARTH ORBITAL ENVIRONMENT

\author{
SHARON K. RUTLEDGE, * PHILLIP E. PAULSEN, * JOYCE A. BRADY, * AND MICHAEL L. \\ CIANCONE* \\ *NASA Lewis Research Center, 21000 Brookpark Rd., Cleveland, OH 44135 \\ **Cleveland State University, Euclid Ave. at 24th St., Cleveland, OH 44115
}

\title{
ABSTRACT
}

Fiberglass-epoxy composites have been considered for use as structural members for the mast of the space station solar array panel. The low Earth orbital environment in which space station is to operate is composed mainly of atomic oxygen, which has been shown to cause erosion of many organic materials and some metals. Ground based testing in a plasma asher was performed in order to determine the extent of degradation of fiberglass-epoxy composites when exposed to a simulated atomic oxygen environment. During exposure, the epoxy at the surface of the composite was oxidized, exposing individual glass fibers which could easily be removed. Several methods of protecting the composite were evaluated in an atomic oxygen environment and with thermal cycling and flexing. The protection techniques evaluated to date include an aluminum braid covering, an indium-tin eutectic, and a silicone based paint. The open aluminum braid offered little protection while the CV-1144 coating offered some initial protection against atomic oxygen. The In-Sn eutectic coating provided initial protection against atomic oxygen, but appears to develop cracks which accelerate degradation by atomic oxygen when flexed. Coatings such as the In-Sn eutectic may provide adequate protection by containing the glass fibers even though mass loss still occurs.

\section{INTROOUCTION}

One of the major power components of the space station is the photovoltaic power module [1]. The solar array assembly, which is one component of the module, contains (1) a pair of polyimide (Kapton@) solar array blankets which provide structural support for the solar cells and circuitry, and (2) a mast to provide on-orbit deployment of the solar array blankets while maintaining blanket structural support and rigidity when extended [1]. The mast structural elements are fiberglass-epoxy longerons which run the length of the structure and coil into a canister when the mast is retracted. A complete description of the mast and its relation to the solar array assembly is given in reference 2 .

Since the fiberglass-epoxy mast will be exposed to the low Earth orbital (LEO) environment; it must be resistant to attack by atomic oxygen which is the most predominant species from 180 to $650 \mathrm{~km}$ altitude [3]. The mechanism of degradation is believed to be the breaking of chemical bonds such as $\mathrm{C}-\mathrm{C}$ through impact with energetic ( 4.2 to $4.6 \mathrm{eV}$ ) [5] atomic oxygen which will subsequently allow the surface to be oxidized [4]. Many materials, including epoxy, are susceptible to degradation by atomic oxygen [5]. In addition to atomic oxygen, the mast as well as any protection technique must be able to survive other environmental hazards including thermal cycling [6], ultraviolet radiation [6], and impact from micrometeoroids and debris [7]. 
This paper discusses results from a test program to determine whether fiberglass-epoxy longerons need to be protected and how well some candidate protection techniques function in the LEO environment. In this test program, samples were first dehydrated to remove water and absorbed gases that could introduce error into mass measurements. Samples were then exposed to atomic oxygen in an RF plasma asher followed by thermal cycling, flexing, and further atomic oxygen exposure. These tests were performed sequentialiy in order to simulate the environment that the space station will experience. Thermal cycling and flexing followed atomic oxygen exposure in order to determine if areas affected by atomic oxygen would be more likely to fall when being thermal cycled or flexed. The atomic oxygen exposure following this was performed in order to make any defects produced during thermal cycling or flexing more pronounced and to look for synergistic effects. Samples were characterized by mass measurements and scanning electron microscopy.

\section{APPARATUS AND PROCEDURE}

Longerons, Protective Coatings, and Protective Coverings

The fiberglass-epoxy longerons supplied by AEC Abel Engineering that were used in these tests had rectangular cross sections of 0.64 by $0.74 \mathrm{~cm}$ with rounded edges and lengths of $12.7 \mathrm{~cm}$. The longerons contained 19 to 22 percent amine cured epoxy resin by weight; the remainder was composed of $\mathrm{S}-2$ glass fibers. The longeron size and type selected for testing were based on avaflability and the uniformity of the oxidative mass loss rate between various diameters and types of longerons.

Three types of candidate protective coverings or coatings have been evaluated for protection of the fiberglass-epoxy to date. These are an open aluminum braid, an In-Sn eutectic coating (primer/electroless nickel/immersion coated gold/indium-tin eutectic) applied by Composite Optics Inc., and a silicone based paint (CV-1144) manufactured by McGhan Nusil.

\section{Dehydration and Rehydration}

Many polymeric materials absorb water from the atmosphere. The amount of water absorbed depends greatly on the humidity of the environment. If a very strict humidity controlled environment is not maintained, large errors in measured mass loss can occur. If a material can be fully dehydrated and then weighed, the error due to water uptake can be eliminated. It is not always possible to perform in-situ mass measurements, however, so an accurate determination of the time needed to dehydrate a sample and a determination of the rate at which it absorbs water upon removal from vacuum is needed.

Dehydration was performed in a vacuum ranging from 30 to $70 \mu \mathrm{m}$ of $\mathrm{Hg}$. Samples were weighed at atmospheric conditions before and at selected intervals after being placed in vacuum, then returned to vacuum within 3 min to minimize the time they were exposed to the atmosphere. The time to reach equilibrium varied depending on the longeron protection technique. The percentage of mass lost versus time for protected and unprotected longerons is shown in figure 1. Typically, 5 days in vacuum is needed for unprotected fiberglass-epoxy to reach equilibrium. The rate of rehydration was evaluated by monitoring the mass of mc:sture uptake in fully dehydrated samples which were exposed to atmospheric 
pressure in an environment with humidities ranging from 20 to 70 percent. After several days of atmospheric exposure, the mass gain due to rehydration is dependent upon the humidity of the environment, while the mass gain for short (less than or equal to $3 \mathrm{~min}$ ) exposures is nearly fixed. If a sample can be removed rapidly from vacuum and weighed early enough to minimize the effects of humidity, then an accurate mass measurement can be made. Typically, 5 min was found to be a reasonable limit to the time that the samples could be exposed at atmospheric pressure.

\section{Atomic Oxygen Durability Testing}

Atomic oxygen durability testing was performed in an RF (13.56 MHz) air plasma asher (SPI Plasma Prep II). Samples were exposed directly in the plasma with typical pressures of 50 to $120 \mu \mathrm{m}$. The plasma in the asher contains atomic oxygen and nitrogen in various energy states and levels of ionization. Even though there is mainly nitrogen in the plasma, the reacting specie appears to be atomic oxygen [8]. Typical effective fluxes of atomic oxygen based on erosion yields $\left(3 \times 10^{-24} \mathrm{~cm}^{3} / \mathrm{atom}\right)$ of polyimide Kapton ${ }^{\circledR}$ from in space tests were approximately $3 \times 10^{15}$ atoms $/\left(\mathrm{cm}^{2} \mathrm{sec}\right)$ during exposure of the fiberglass-epoxy. Although the flux is higher and the energy is lower (a few tenths of an eV) in ashers than in LEO, exposure in an asher can provide a good qualitative indication of material survivability in LEO. Those materials which survive in an asher appear to survive in LEO, and those that fail in an asher have also failed in LEO.

\section{Thermal Cycling}

Thermal cycling was performed on the longerons in order to determine if thermal expansion mismatch between the protective coatings or coverings and the fiberglass-epoxy would play any role in the ability of the protective layer to adhere to the substrate. Thermal cycling was performed at atmospheric pressure by cycling samples between a nitrogen gas filled chamber heated with coils and a chamber filled with cold nitrogen gas. Samples were transferred between the two chambers using a lever arm assembly that was triggered by a thermocouple mounted on the sample tray. For these tests, the thermocouple was placed inside one of the longerons by drilling a hole down the center of the longeron that was just large enough for the thermocouple wire to enter. Samples were moved from one chamber to the next when the temperature at the center of the longeron reached either +80 or $-80^{\circ} \mathrm{C}$. Each longeron was thermal cycled a total of 413 cycles and spent an average of $4 \mathrm{~min}$ in each chamber.

\section{Flexure Testing}

Flexure testing was performed in order to simulate the extension and retraction of the mast from the mast canister. During storage, the longerons are coiled into a canister whose typical diameter is $66 \mathrm{~cm}$. Longeron samples, both protected and unprotected, were flexed and then straightened with the aid of a clamping fixture to the radius of curvature they would experience in the canister for a total of 100 cycles. This corresponds to a surface strain per cycle of 0 to approximately 1 percent. The mast extension and retraction may occur only 10 to 20 times during the life of the space station, so this is a more severe test of the mast flexural durablitity. 
RESULTS AND DISCUSSION

\section{Durability Testing of Unprotected Fiberglass-Epoxy}

Unprotected longerons were exposed to atomic oxygen in a plasma asher for $1747 \mathrm{hr}$. Figure 2 displays the mass loss versus plasma exposure time for two longerons which were exposed in the asher chamber simultaneously but at different spatial locations. A sample of polyimide Kapton ${ }^{\circledR}$ was included for comparison. The longeron data agree well with each other and with other longeron mass loss data. It was initially believed that since the oxidation rate of glass is very low, while that of epoxy is relatively high as observed on STS-8 [5], that the outer layer of epoxy would be removed but the underlying fibers would provide a barrier to further oxidation by preventing line-of-site oxidation of the remaining epoxy. The results seem to indicate that epoxy continues to be removed at a constant rate even after the outer surface of epoxy is no longer present. The change in mass loss rate that occurs at approximately $200 \mathrm{hr}$ for these samples (figure 2) is unique to the fiberglass-epoxy longerons. The Kapton ${ }^{\odot}$ loss rate remained constant during this time, which indicates that the change in mass loss rate is not due to any changes in the plasma conditions. It is probable that since the outer surface of the longeron is initially completely covered by epoxy, this layer is removed at a higher initial rate because there is no shielding by the glass fibers. Once the fibers are exposed, the rate declines to a new constant which is related to the resin fill percentage. Assuming that after $200 \mathrm{hr}$ the fiberglass-epoxy ratio for these samples is equal to the fill percentage at the surface and the fiberglass does not lose mass, the calculated rate of epoxy removal after $200 \mathrm{hr}$ nearly matches the initial epoxy loss rate. This strongly suggests that the change in slope is due to a change in the amount of epoxy exposed and not the oxidation rate. Perhaps the most alarming result is that the fiberglass does not afford any atomic oxygen shielding of the deep, visually hidden, underlying epoxy.

Over the space station array lifetime of 15 years, which corresponds to approximately $390 \mathrm{hr}$ of exposure in the asher plasma, the mass that is lost is not large enough to cause a significant change in the tensile modulus of the fiberglass-epoxy [2]. However, after only 50 to $200 \mathrm{hr}$ of asher plasma exposure which corresponds 2 to 8 years in space station orbit, individual glass fibers are already being exposed (figure 3 ). These fibers are very brittle and can break off due to flexure. This may lead to contamination problems for space station components and could cause difficulty in mast retraction if the friable, loose glass fibers get into the rollers or track and create friction in the extension, and retraction mechanism. Figure 4 shows a fiberglass epoxy longeron that was unexposed and one that was exposed for $1747 \mathrm{hr}$. This illustrates the extent of epoxy removal and fiber exposure that can occur. The extent of fiber removal is serious enough that the application of some protective covering or coating to the fiberglass-epoxy is needed to keep the fibers from leaving the surface. The protection required must also be able to survive the surface strain levels $(\varepsilon \approx 1$ percent) experienced by the retracted longeron.

Durability Testing of Protected Fiberglass-Epoxy

Three protective coatings or coverings were evaluated for fiberglassepoxy longerons. All protected samples were exposed to atomic oxygen in the 
asher plasma for $100 \mathrm{hr}$ to determine the durability of the protected longerons to atomic oxygen. The results of this exposure are shown in figure 5 . Although an open aluminum braid provides some initial protection to the fiberglass-epoxy, it begins to lose mass at the same rate as the unprotected sample after approximately $24 \mathrm{hr}$ in the plasma. The CV-1144 silicone paint provided good initial protection to the fiberglass-epoxy longeron. After $100 \mathrm{hr}$, however, there appeared to be areas in the painted surface where the paint had been removed and individual fibers were beginning to become visible. The In-Sn eutectic coating appeared to provide the best initial protection to the longeron for the coatings and coverings evaluated to date.

After atomic oxygen exposure, the In-Sn eutectic coated longeron and the unprotected longeron were thermal cycled and flexed. The same testing will be performed with the $A 1$ braid and $C V-1144$ coated longerons at a later date. Mass loss versus atomic oxygen exposure time after thermal cycling, flexing for the unprotected, and In-Sn eutectic protected longerons is given in figure 6 . The unprotected sample lost mass at approximately the same rate as discussed previously, while the In-Sn eutectic coated fiberglass-epoxy mass loss increased after approximately 150 total hours of plasma exposure. Preliminary results indicate that flexing of the In-Sn eutectic coated longeron may produce cracks in the coating which could allow exposure of the underlying surface to atomic oxygen. Even though some mass loss occurs, the coating appears to be intact on the surface and no individual fibers were visible after $200 \mathrm{hr}$ total of plasma exposure.

\section{CONCLUSIONS}

Fiberglass-epoxy longerons undergo mass loss upon exposure to atomic oxygen. Even though the mass loss is not significant over the life of space station from a structural standpoint, the removal of epoxy to expose brittie glass fibers which can break off during handling or extension and retraction of the mast could be a significant concern. Of the three protective coatings or coverings evaluated, open aluminum braid provides little protection, CV- 1144 silicone paint offers some initial protection against atomic oxygen, and the In-Sn eutectic coating provides initial protection against atomic oxygen, but appears to develop cracks which accelerate degradation by atomic oxygen when flexed.

Providing a coating which can contain the fiberglass fibers may be more important than preventing mass loss for this composite. If a coating can survive atomic oxygen exposure, thermal cycling, and flexing to the extent that an adherent layer is maintained over the longeron which prevents fiberglass fibers from breaking off, it may be adequate. It appears that the In-Sn eutectic and possibly the CV-1144 silicone may provide this type of protection. More testing needs to be performed in order to determine if coatings of the type evaluated here can withstand UV degradation, micrometeoroid exposure, and an atomic oxygen exposure equivalent to 15 years in LEO.

\section{REFERENCES}

1. C.R. Baraona, "The Space Station Power System," NASA TM-88847, 1986. 
2. M.L. Ciancone and S.K. Rutledge, "Mast Material Test Program (MAMATEP)," AIAA Paper 88-2475, Apr. 1988. (NASA TM-100821).

3. "U.S. Standard Atmosphere, 1976," NASA TM-X-74335, 1976.

4. R.H. Hansen, J.V. Pascale, T. DeBenedictis, and R.M. Rentzepis, J. Polym. Sci. A, $\underline{3}, 2205-2214$ (1965).

5. B.A. Banks, et al, in Eighteenth IEEE Photovoltaic Specialists Conference. (IEEE, New York, 1985) pp. 381-386.

6. H.S. Rauschenbach, Solar Cell Array Design Handbook. (Van Nostrand Reinhold Co., New York, 1980).

7. M.J. Mirtich, "The Effect of Near Earth Micrometeorite Environment on a Highly Reflective Mirror Surface," Presented at the AIAA Meeting, Reno, NV, Jan. 1988 (to be published as a NASA TM).

8. S.K. Rutledge, et al., "An Evaluation of Candidate Oxidation Resistant Materials for Space Applications in LEO," NASA TM-100122, 1986.

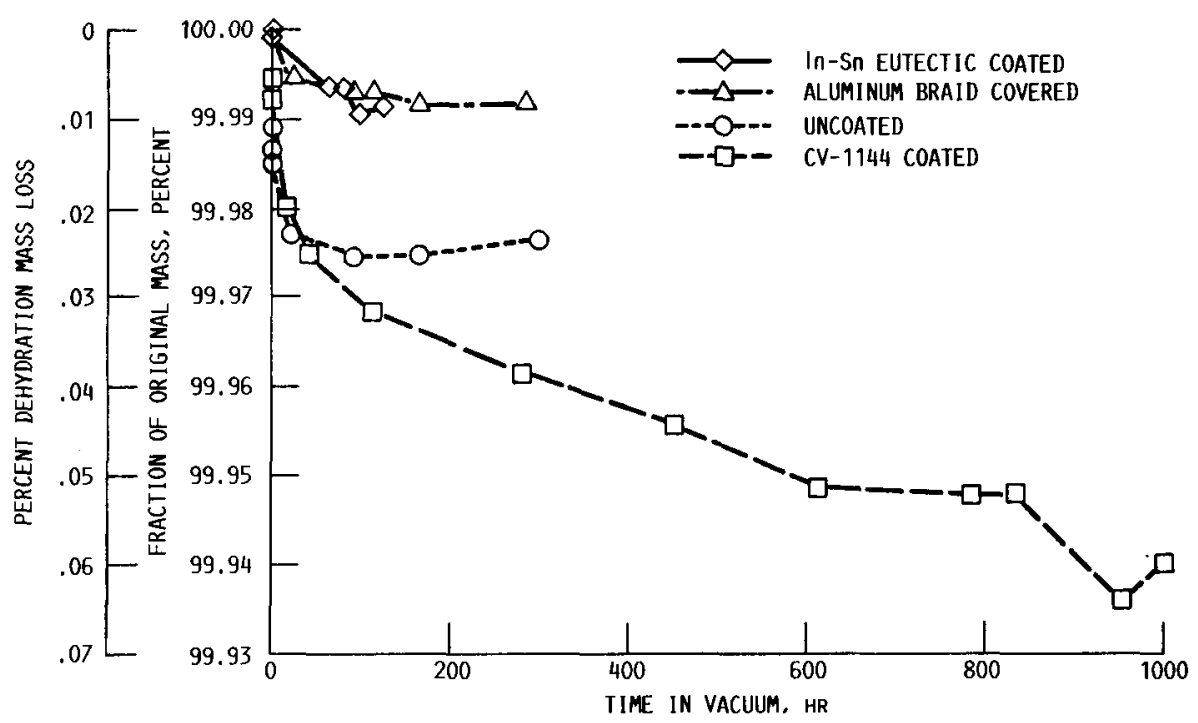

FIGURE 1. - DEHYDRATION OF PROTECTED AND UNPROTECTED FIBERGLASS-EPOXY. 


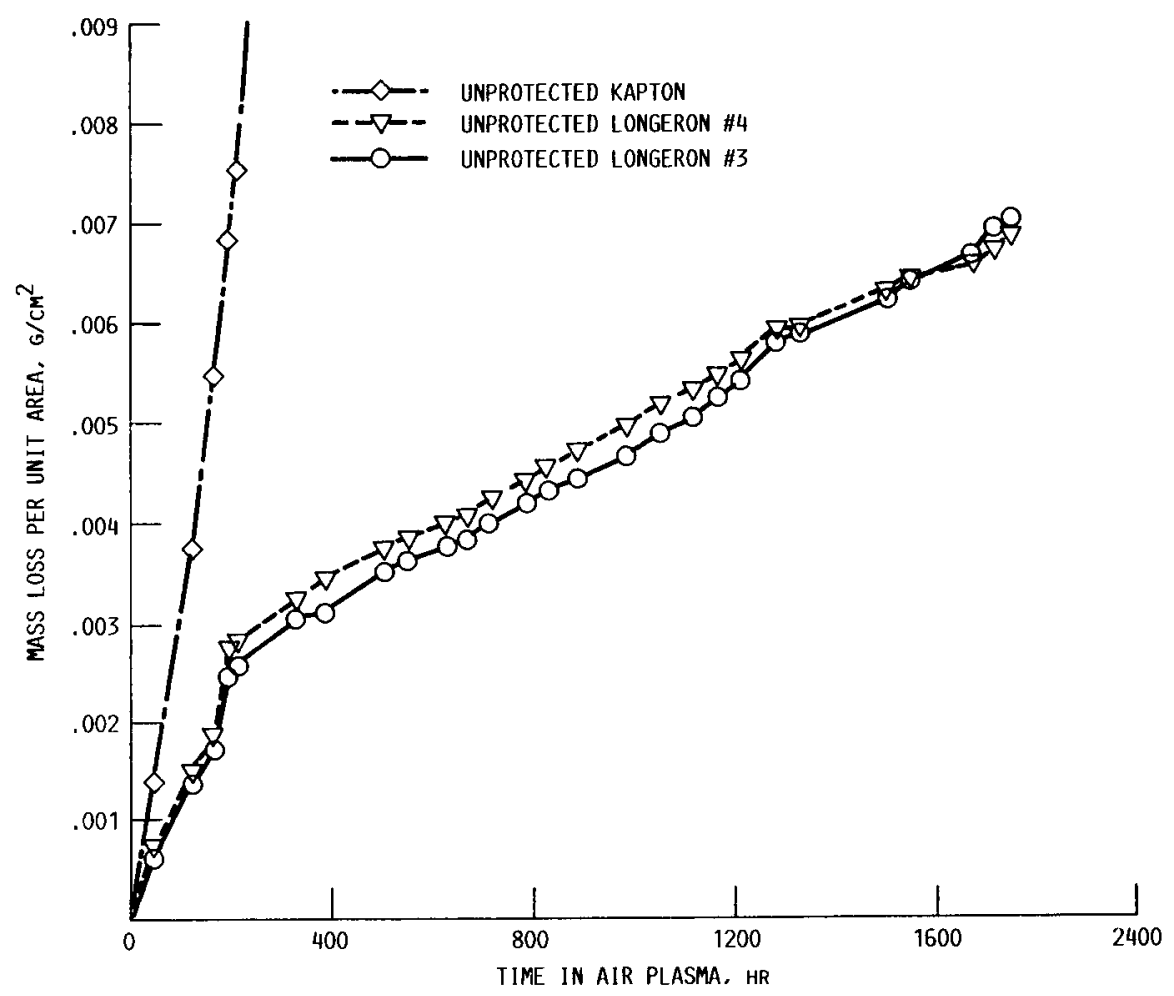

FiguRE 2. - MASS LOSS VERSUS PLASMA EXPOSURE TIME FOR UNPROTECTED FIBERGLASS EPOXY. 


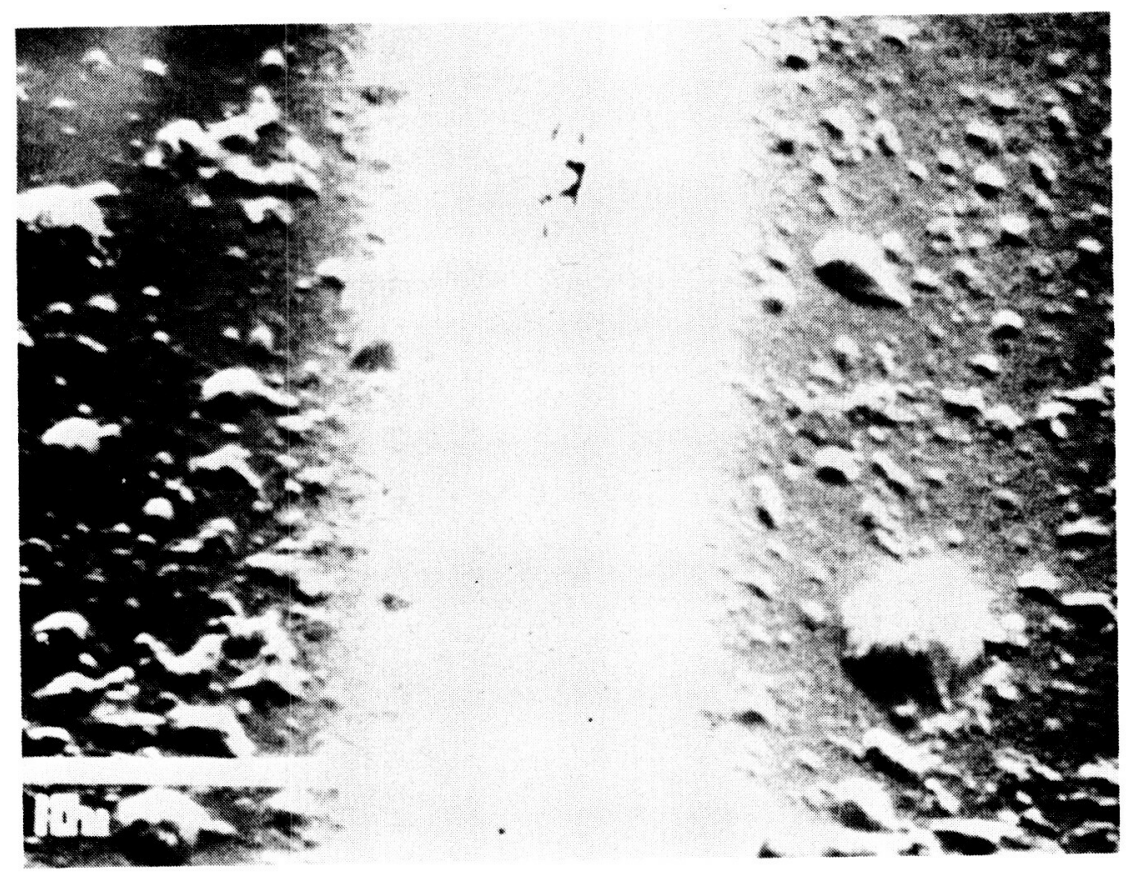

(A) UNEXPOSED.

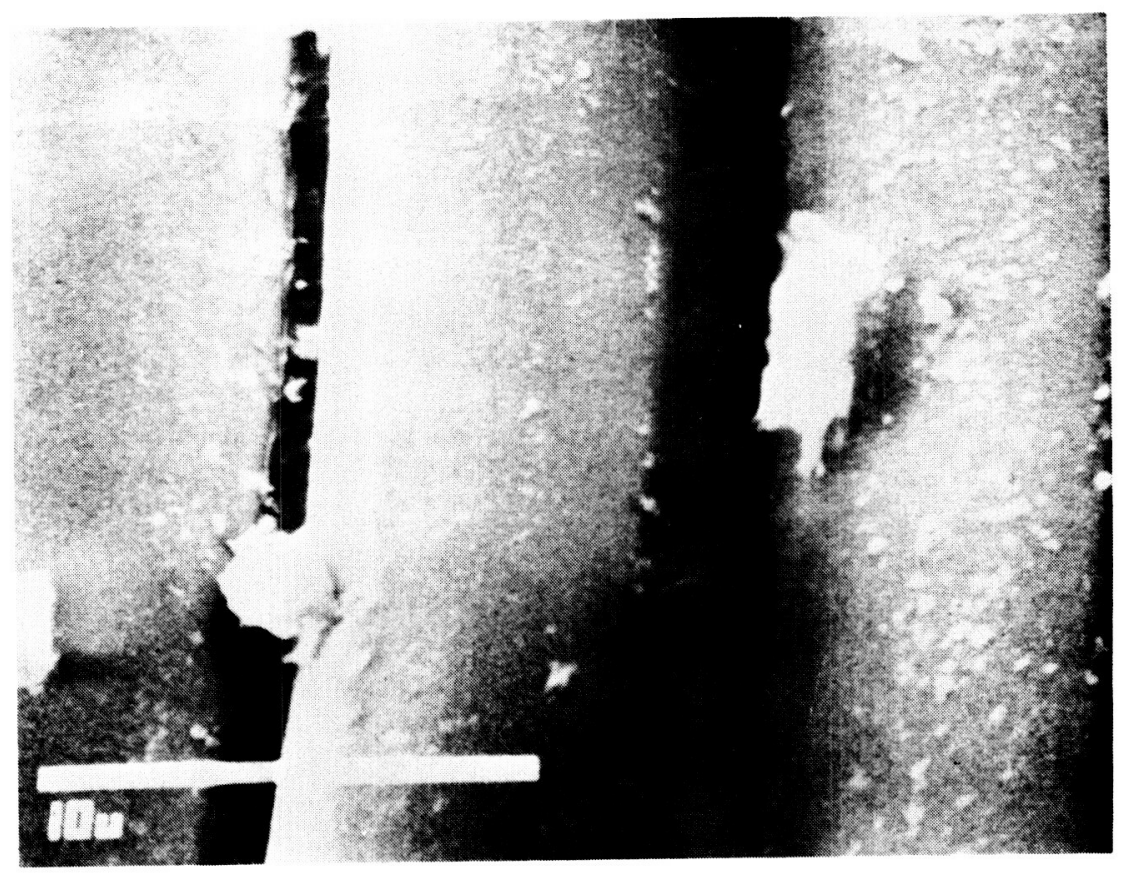

(B) EXPOSED TO PLASMA 50 HR SHOWING INDIVIDUAL GLASS FIBERS AND LACK OF EPOXY.

FIGURE 3. - SCANNING ELECTRON PHOTOMICROGRAPHS OF FIBERGLASS EPOXY. 


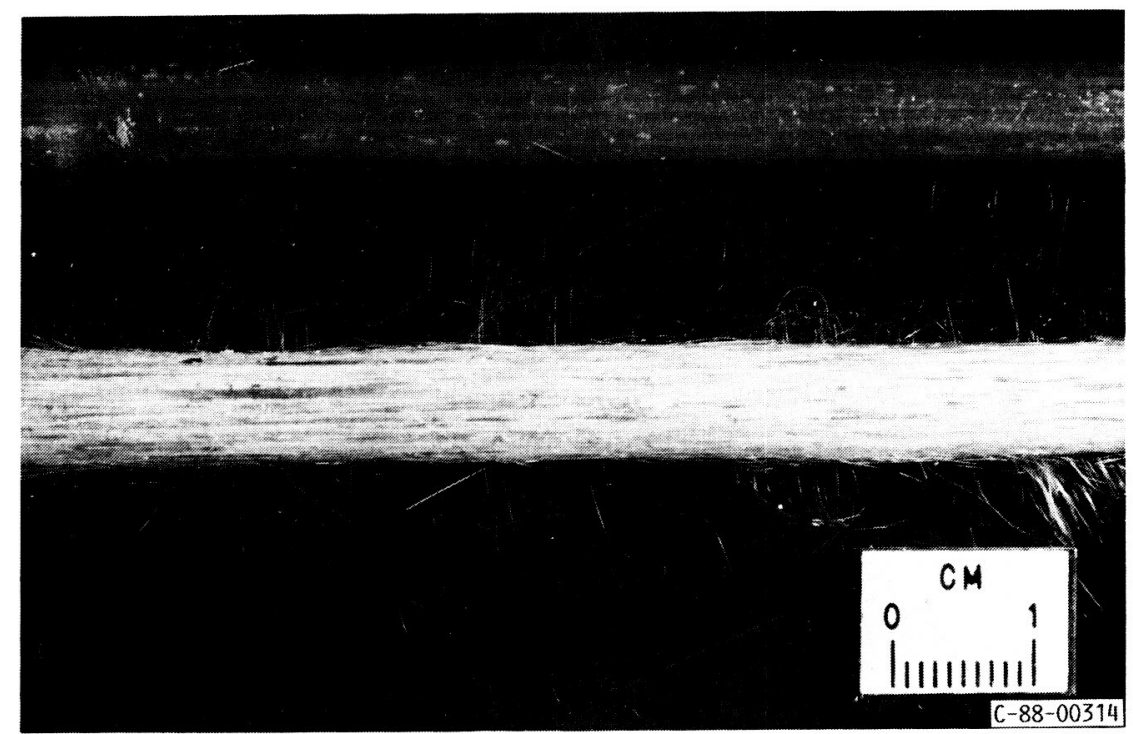

FIGURE 4. - UNEXPOSED (TOP) AND PLASMA EXPOSED 1747 HR (BOTTOM) FIBERGLASS-EPOXY.

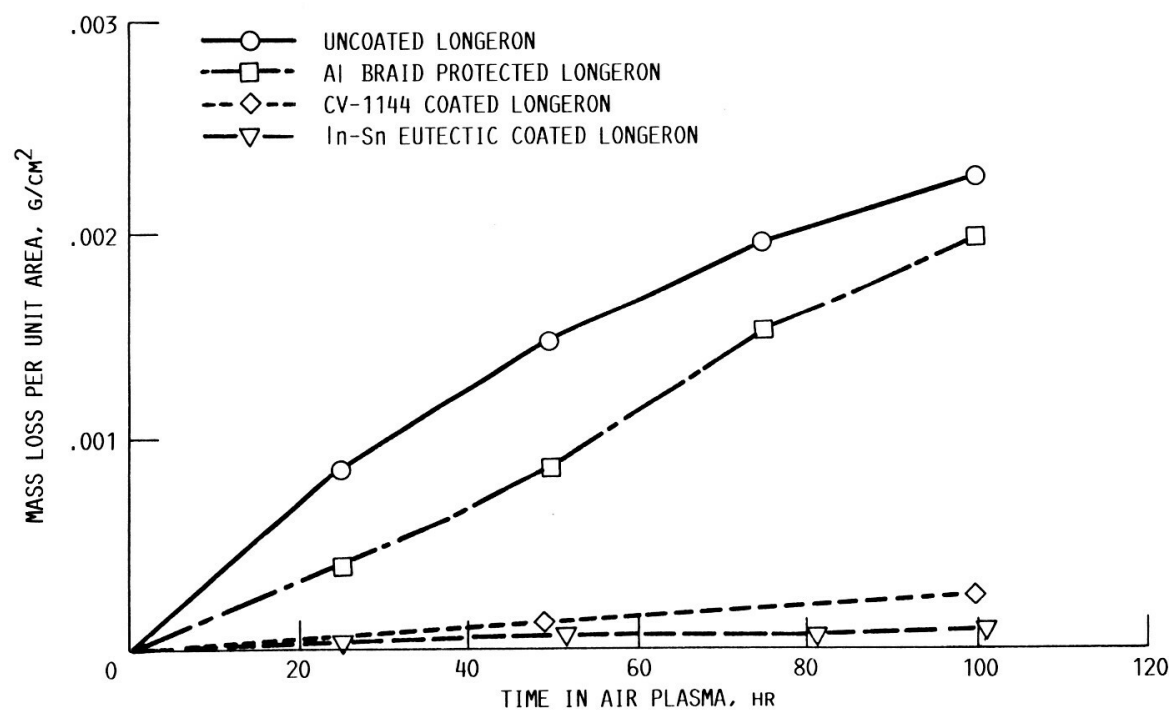

FIGURE 5. - MASS LOSS COMPARISON OF PROTECTED AND UNPROTECTED LONGERONS. 


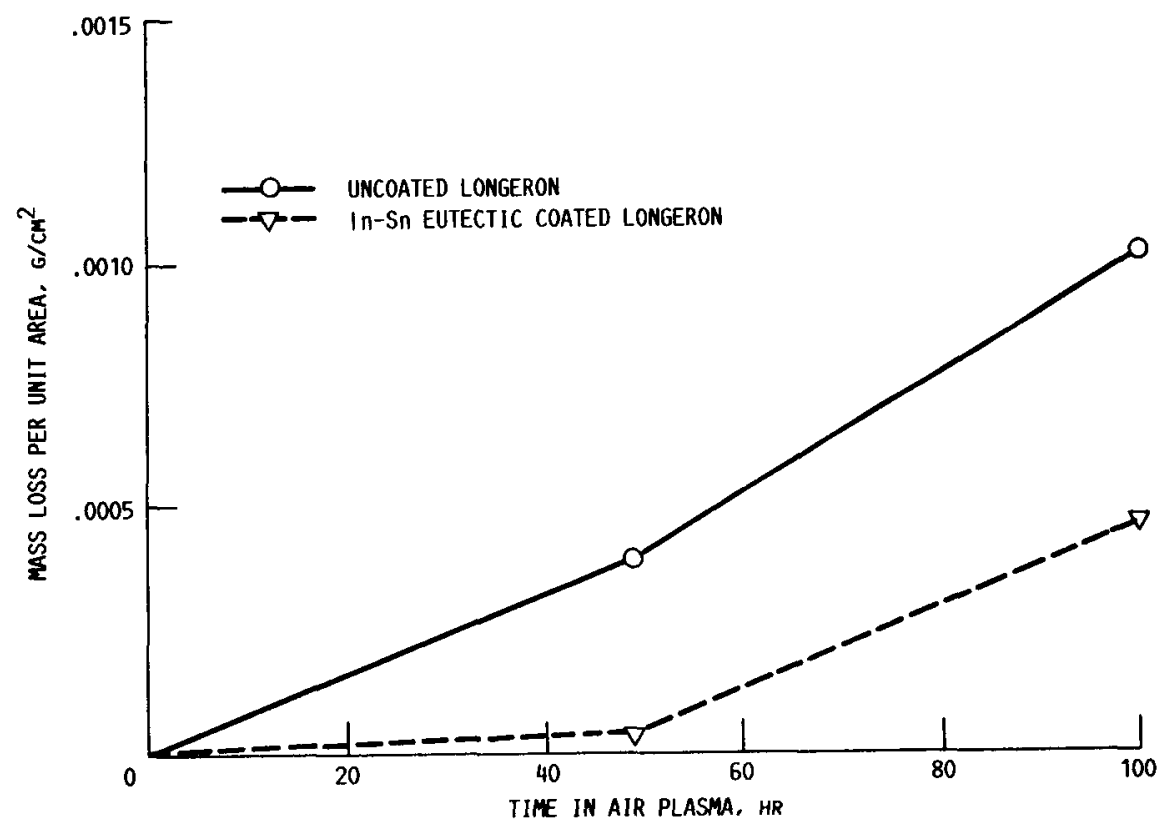

FIGURE 6. - MASS LOSS COMPARISON OF PROTECTED AND UNPROTECTED LONGERONS THAT HAVE BEEN PLASMA EXPOSED 100 HOURS THEN THERMAL CYCLED, AND THEN FLEXURE TESTED. 


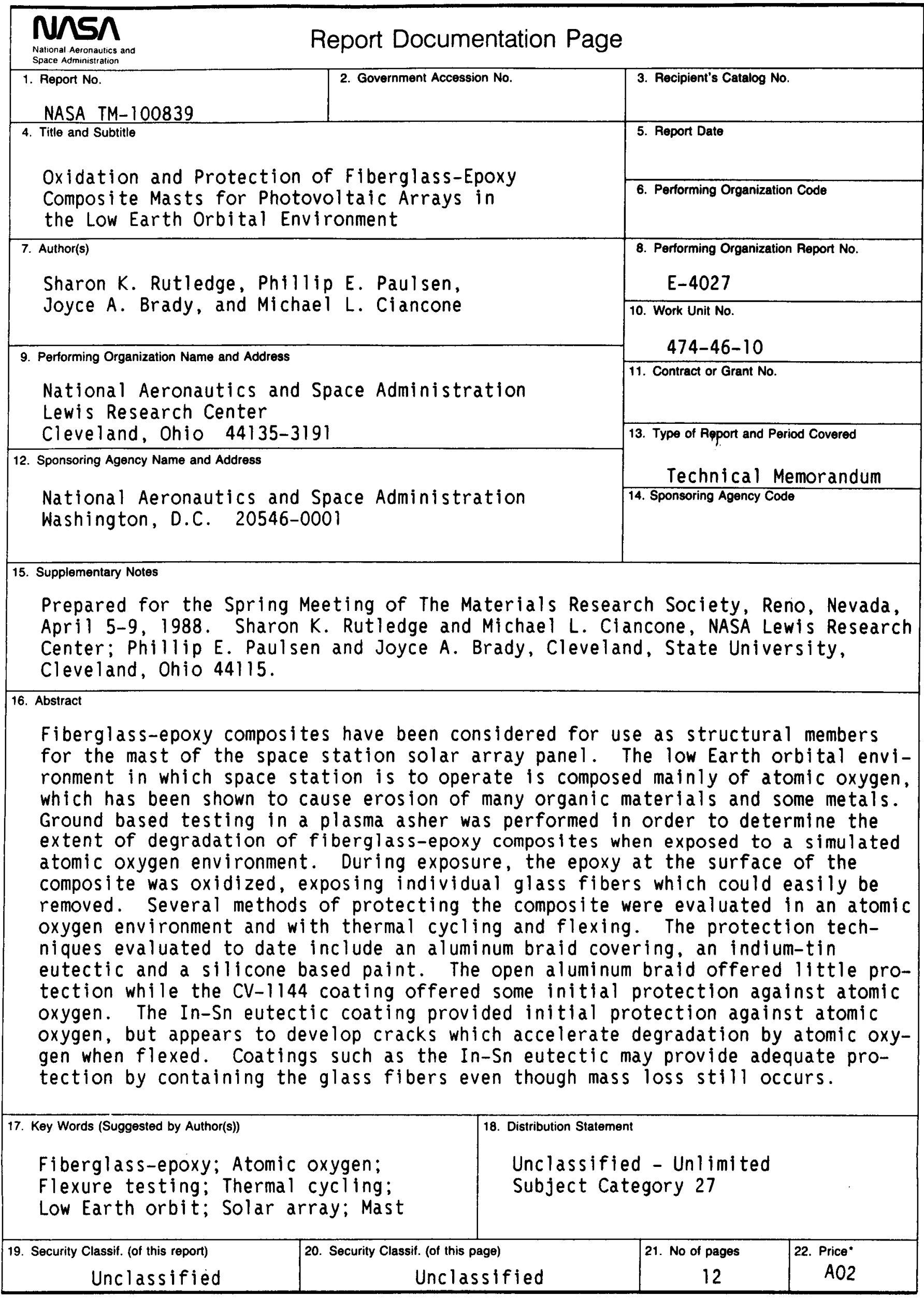

